\title{
Future EU-UK research and higher education cooperation at risk: what is at stake?
}

\author{
Ludovic Highman ${ }^{1}$ \\ Published online: 18 December 2018 \\ (C) The Author(s) 2018
}

\begin{abstract}
The UK higher education sector has entered a period of turbulence, as the consequences of the UK leaving the European Union (EU) hit home. Higher education institutions are bracing themselves for what will no doubt be a period of substantial change, uncertainty and challenge. The complexity of the intricate relationships linking EU member states, as well as the EU institutions and their member states, appears to have been misunderstood and understated in the UK, by both the political class and the general public, at the time of the June 2016 referendum. If information is indeed power, its current unavailability is a concern, given that the UK government's plans to remain firmly embedded within the European Research Area and the Erasmus+ programme remain non-committal. In what can be described as a game of high politics between the EU and the UK government, the fate of research and higher education collaboration will be sealed by high-level inter-governmental agreements decided behind closed doors.
\end{abstract}

Keywords Brexit · Higher education · Research · Science · European Union · Association agreement

\section{Introduction and relevance of the topic}

Research and science are inherently cross-border, transnational activities. There is no single discipline, university or country, however prestigious, that can tackle the global challenges of today on its own. Excellent, high impact science requires cross-border cooperation between universities and research institutes in different countries, employing staff with different nationalities, enabling swift circulation of ideas and talent.

It has been demonstrated that greater impact is gained through international co-authored publications, which are on average more highly cited than UK domestic publications. For the UK, that cooperation currently takes place for the larger part with EU partners: 13 out of the 21

Ludovic Highman

ludovic.highman@gmail.com

1 University College London, London, UK 
countries (Universities UK, April 2017: 8) that have co-authored at least 1\% or more of UK research outputs during 2007-2016 are EU countries (rising to 15 countries if Horizon 2020 non-EU associated countries Norway and Switzerland are included). While the UK is a partner of choice for each of its European collaborators, on the flip side the quality and impact of UK research, science and innovation depends on interaction with all 15 of these European countries simultaneously.

Unless a (re)new(ed) EU-UK partnership in research, science and higher education is swiftly agreed, the UK's science and higher education sectors will suffer from a lack of connectivity to EU partners, whether with regard to research collaboration or student and staff mobility. More uncertainty and delays will only further damage the research output of all EU universities, and diminish mobility opportunities for students and staff, while isolating the UK from its region. In order to prevent such an unfortunate scenario for European (including British) science, agreeing rapidly - and independently from the broader, final high-level Brexit negotiations - an EU-UK research and higher education deal, including at the very least 'associate country' status for the UK, is of the essence.

Access to the multi-billion EU framework programmes implies EU membership, although full association to the current $€ 80$ billion Horizon 2020 research and innovation programme is possible for non-EU countries. However, association is part of the EU's 'soft power' portfolio (Highman 2018), targeting mainly EU candidate countries and capacity building in the development of higher education in the European Neighbourhood Policy. There are 16 associated countries in the current research framework programme, Horizon 2020 (20142020), and only Israel, Norway and Switzerland are home to institutions that are highly successful in securing EU funds based on excellence (European Commission(a): 2014). Association is a mechanism whereby legal entities (for example universities) from associated countries can participate under the same conditions as legal entities from EU member states. It should be noted that association to Horizon 2020 takes place through the conclusion of an International Agreement between the EU and the associated partners, and that under the current association rules, an associated member has no voting rights (Papatsiba and Highman 2017: 2).

The paper looks at what are the priorities needed to be examined in order to ensure the smooth continuity of research and science, and the continued excellence of European (including British) science, focussing in particular on future eligibility of UK universities to EU research funded schemes and Erasmus+ mobility opportunities.

\section{Eligibility of UK partners for the EU research \& innovation programmes}

The intertwined relationships between EU members and institutions are particularly evident in research and higher education, where the UK is a net beneficiary of the EU Research \& Development (R\&D) budget, with several of its universities ranking among the top performers (see Table 1). Articles 165 and 166 of the Treaty on the Functioning of the European Union give power to the EU to operate as a major player in supplementing and supporting EU member states' higher education and vocational training policy. With regard to research and technological development, Articles 179-190 give the EU a steering role in adopting and implementing multiannual framework programmes.

The potential damage of a no deal scenario in higher education and research is not limited to those top Horizon 2020 performers, with the universities of Cambridge, Oxford and UCL 
Table 1 Number of project participations and EU contribution by higher education institution

\begin{tabular}{llc}
\hline Legal name & $\begin{array}{l}\text { EU contribution } \\
\text { (EUR) }\end{array}$ & $\begin{array}{l}\text { Project } \\
\text { participations }\end{array}$ \\
\hline 1. University of Cambridge & $277,593,353$ & 438 \\
2. University of Oxford & $268,577,802$ & 409 \\
3. University College London (UCL) & $261,249,501$ & 402 \\
4. University of Copenhagen & $183,309,642$ & 369 \\
5. Imperial College London & $181,196,668$ & 306 \\
6. Swiss Federal Institute of Technology in Lausanne (EPFL) & $176,345,302$ & 254 \\
7. Catholic University of Leuven (KU Leuven) & $174,628,619$ & 332 \\
8. University of Edinburgh & $171,942,636$ & 257 \\
9. Delft University of Technology & $167,182,232$ & 275 \\
10. Swiss Federal Institute of Technology in Zurich (ETH Zurich) & $148,577,050$ & 266 \\
\hline
\end{tabular}

European Commission(f), Participant Portal, Horizon 2020 data, 29 September 2018

currently the three most successful university recipients of Horizon 2020 funding in Europe, and another two British institutions ranked in the top ten. Imperial College London has been overtaken by the University of Copenhagen for the first time since the interim evaluation of Horizon 2020, that took into account grants signed off before the 01 January 2017 (European Commission(b) 2017: 229). This ranking is subject to regular minor fluctuations as new grants are awarded to successful bids.

These high performing higher education institutions are only the tip of the iceberg. The percentage of EU research income as a proportion of total research income received is particularly alarming at some mid- or lower ranked universities, with more than 40 institutions with dependency ratios above 20\% (see Table 2, Technopolis 2017: 20). When compared to those top Horizon 2020 performers in Table 1, the research funds secured by universities in Table 2, a majority of which are former polytechnics, are relatively modest in absolute terms, because the amounts are commensurate to their overall research capacity.

While Oxford, Cambridge and some other Golden Triangle universities may be able to soften the blow thanks to their recognised international brands and diverse research funding portfolios, this will certainly not be the case for all UK universities, and in particular those with high EU research funding dependency ratios, regardless of the amounts in absolute terms. A much larger segment of the UK higher education sector is at risk, one whose graduates are under-represented in Westminster and within the UK government, and it is the latter that has most to lose.

Table 2 The 10 Institutions that received most income from EU government bodies as a proportion of total research income, in $£$ thousands

\begin{tabular}{lll}
\hline 1. Goldsmiths College (University of London) & $£ 3371$ & $61 \%$ \\
2. Middlesex University & $£ 1 \%$ \\
3. University of South Wales & $£ 2532$ & $41 \%$ \\
4. Birmingham City University & $£ 2271$ & $40 \%$ \\
5. Anglia Ruskin University & $£ 1033$ & $40 \%$ \\
6. Aston University & $£ 1324$ & $39 \%$ \\
7. Bangor University & $£ 5589$ & $38 \%$ \\
8. Sheffield Hallam University & $£ 8306$ & $35 \%$ \\
9. University of Wolverhampton & $£ 2811$ & $35 \%$ \\
10. Coventry University & $£ 1040$ & $33 \%$ \\
\hline
\end{tabular}

Technopolis (2017) 
The European Commission has made it clear that it will not fund UK-based researchers or universities and research organisations beyond the exit date of the UK in March 2019, hence before the end of Horizon 2020, should no deal have been reached. Since this is an increasingly likely outcome, with key UK government officials suggesting the chances of a no deal are at '60-40' (Fox, 05 August 2018), it is worth pondering on the following: "if the United Kingdom withdraws from the EU during the grant period without concluding an agreement with the EU ensuring in particular that British applicants continue to be eligible, you will cease to be eligible to receive EU funding (while continuing, where possible, to participate) or be required to leave the project on the basis of Article 50 of the grant agreement" (European Commission(d), added on 06/10/2017).

Although the UK Treasury has recently committed to underwrite any funding secured through EU programmes until the end of 2020, even in a no deal scenario (HM Government(c) 2018), research collaboration relies on continued interaction, consistency and trust forged over long timeframes, from both sides. Government updates on research funding are episodic and haphazard, demanding constant tracking and ultimately resources to keep oneself updated with the latest developments. While evidence of UK partners being asked not to join or leave current research consortia is either anecdotal or currently not available, there is increasing evidence that UK coordinating or leadership roles have been or are jeopardised.

\section{Erasmus+}

Beyond research and innovation funding, Erasmus+, the EU's all-encompassing programme to support education, training, youth and sport in Europe (2014-20), with an allocated budget of $€ 14.7$ billion, provides a successful framework for student and staff mobility, and offers opportunities for UK universities to increase their connections and competitiveness. The enrichment of the overall student experience that is provided by Erasmus+ is difficult to quantify but vital to the diversity of UK campuses, as is the added value of better language skills. Alternative mobility schemes will have to be devised, and while 'going global' sounds appealing, it should not be assumed that the demand for it exists within the UK-based student body. Already, intra-European mobility remains a privilege for only a minority because of the associated costs. Future opportunities in Australia, New Zealand and North America will be more expensive, and will not benefit from EU financial support towards the cost of living abroad.

Some UK universities are already taking it onto themselves to create small informal European networks for enhanced research and mobility collaboration, and putting aside mobility scholarships, but many universities do not have the resources to single-handedly replace a pan-European mobility scheme of the likes of the Erasmus+ programme with their own initiatives. Exchange agreements are usually based on the principle of reciprocity, and students on both sides of the exchange benefit from EU-funded monthly allowances, on top of tuition fee waivers. Should the UK not participate in Erasmus+, it will be a case not only of funding outgoing UK-based students, but of finding ways to enable EU-based students to still somehow access similar financial support in order to study at a UK-based university.

In short, Erasmus+ offers a supportive framework to nurture exchanges, with its own substantial budget enabling a reciprocal flow of students and for the administration of these exchanges. Without such financial support, UK universities will have to draw from their own resources, both financial and human, to recreate similar arrangements at a higher cost. 
According to the latest Brexit White Paper (July 2018), education cooperation, notably that centred around Erasmus+, would be part of an EU-UK "culture and education" cooperative accord that would allow for UK HEIs' participation in EU mobility programmes. The Brexit White Paper devotes a single bullet point to the topic, noting that the end of the current Erasmus+ scheme in 2020 will coincide with the end of the UK's transition period. The UK remains noncommittal but "open to exploring participation in the successor scheme" (HM Government(b) 2018: 79). However, should the UK secure a close economic partnership with the EU, it would seek to provide reciprocal arrangements with regard to mobility. These would nonetheless be "consistent with the ending of free movement", and would "facilitate mobility for students and young people, enabling them to continue to benefit from world leading universities and the cultural experiences the UK and the EU have to offer" (HM Government(b): 33). This position will gain from further discussion with EU negotiators, but appears to be linked to the EU and the UK securing a close trading partnership, and does not seem to anticipate a 'no deal' scenario.

\section{Association status for the UK}

Association to the Framework Programmes has been used by the EU as an instrument of soft power, and has previously focused primarily on capacity-building in the European neighbourhood, targeting first and foremost European Neighbourhood Policy or candidate countries, with a few notable exceptions (Iceland, Norway and Switzerland). The UK clearly does not fit in either category and because of its sheer size, high success rate in winning awards, and refusal to recognise the free movement of people, a mutually beneficial and creative solution for collaboration must be found. This agreement must recognise the positive contribution of British research to European science, while acknowledging that European science is not 'business as usual', and that the UK cannot simply expect or seek to secure a deal that would enable it to make a substantial return on its investment.

Post-2020 EU research and innovation funding programmes should have a global outlook and be open to association for trading partners of a similar level of excellence, such as Australia or Canada, according to a report prepared for the European Commission by the so-called 'High Level Group', chaired by Pascal Lamy, a former Director-General for the World Trade Organization (WTO) and European Commissioner for Trade (European Commission(c) 2017: 21). The report, entitled "Investing in the European future we want" (or Lamy report), sets out to offer a broad vision and strategic recommendations to maximise the impact of post-2020 EU research and innovation funding programmes. However, at present, based on the lack of information provided by both the UK government and EU negotiators, it is impossible to predict if the UK and the EU are on a trajectory to become global trading partners; at least in the short term, quite the contrary would seem to be the case. In a leaked memo said to have been provided to Chief Brexit negotiator Michel Barnier for a "preparatory discussion" on the "framework for the future relationship", it was revealed that the EU is of the opinion that because of the UK's rejection of the European Court of Justice jurisdiction and issues around "regulatory autonomy", it cannot be considered a "compatible" fit as a close trade partner (De la Baume \& Mishcke 2017).

The further emerging crisis surrounding the European Commission's February 2018 Draft Withdrawal Agreement proposal for the Northern Ireland border will only mean further discussions, delay and more uncertainty (European Commission(e) 2018). Hence association 
to the EU research and innovation programmes on the basis of being recognised as a global trading partner is facing considerable bottlenecks. As such, because of the sui generis nature of both the UK's departure and its future relationship with the EU, it may be possible that existing framework agreements for research and innovation with third countries, such as association, are unhelpful. Hence, looking beyond existing partnerships and models may become a more useful exercise than trying to replicate existing arrangements. However, this demands frank and transparent discussions from both sides, a capacity to look beyond national self-interest and domestic point-scoring, as well as an ability to depart from a monolithic standpoint and engage in creative policy thinking.

In addition, the UK, by being geographically speaking a European country, is not necessarily the primary target of the Union's new policy to open European research excellence to the world, which seeks to expand the EU's soft power via science globally. Indeed, the new proposed policy is considered a remedy to the current narrow geographical basis of EU research and innovation programmes, and explicitly justified as a means to widen the currently regionally biased scope of research and innovation excellence, so that it is "not confined to a particular part of the world" (European Commission(c) 2017: 21), that currently being the greater European region and its immediate neighbourhood. Opening European research excellence to the UK would only further emphasise the current regional bias of EU research and innovation programmes, although the Lamy report does vaguely recommend that a "positive cooperation model", one based on mutual investment, should be established to enable "full and continued engagement" with the UK post-Brexit (European Commission(c) 2017: 21). However, the report gives no indication as to how that could be achieved, and it is unlikely that the mutual investment requirement will result in the UK remaining a disproportionately net beneficiary of the EU's R\&D budget, without significant investment into the latter.

\section{Conclusions and policy recommendations}

The "ambitious and close partnership with the EU" referred to in the UK's government "Collaboration in science and innovation: a future partnership paper" (HM Government(a) 2017: 8) should be agreed upon immediately, providing certainty for the higher education sector. Applications for a Horizon 2020 grant are time-consuming. The British Academy has estimated that many collaborative research grant applications in the arts, humanities and social sciences can take more than 18 months to complete (2017). Just like business, research and higher education operate in a space where certainty is vital.

Nonetheless, certainty in the UK is today a scarce if not inexistent resource, where nothing is decided until everything is. Both the quantity and quality of UK bids for EU research grants will suffer because of the time restraints that will de facto be placed on the British academic community. Moreover, the enduring lack of certainty regarding principal investigator status for UK researchers will lead to fewer applications being made. It should be emphasised that this is not a prediction or an economic analysis, it is already the reality. The proportion of EU projects coordinated by British research teams fell sharply after the referendum, from $16.9 \%$ in 2016 to $12.6 \%$ of all funding in 2017, dropping behind Germany (Matthews 2017).

The UK government acknowledges that under current rules, associated countries have no voting rights over the thematic directions of the EU multiannual work programmes nor can they shape funding allocation rationales (HM Government(a) 2017). There is a need for more 
creative policy thinking on both sides to see how the relationship can be mutually beneficial, and not be a case of cherry-picking which sectors have the highest return on investment for one side. The UK has been a strong advocate for funding instruments based purely on excellence. Without the UK, those member states currently supporting an approach focusing only on excellence will have lost their most vocal supporter. However, should UK higher education institutions suddenly be ineligible to compete for EU research funds, higher education institutions in other member countries could see an increase in their success rate for EU grants.

EU and UK universities need to be further included in Brexit-related negotiations, as the nature of a future EU-UK relationship in research and science can only be properly implemented with the support and input of both academic and professional staff, while also including the student voice. Research outputs ultimately generate societal benefits while contributing to solving global societal challenges. Should a deal be negotiated behind closed doors, without a concerted consultation of the relevant stakeholders beyond politicians and policy-makers, it would face an immediate implementation gap detrimental to research, science and society. In the UK, where British society still remains divided over Brexit, the government is keen to distance itself from its universities, perceived to be bastions of implacable remainers. However, this attitude will cripple the government's capacity to achieve a successful deal, and further undermine the value of research and higher education in the UK, and the people who make these sectors the success stories they are today.

Without a substantial UK contribution to the EU's research and development budget, continuing access of UK universities to EU research grants could face legitimacy concerns, at a time where competition between universities is growing and their role in driving national economies is key. It will ultimately be a matter for EU member states, and the EU taxpayer, to decide whether they wish to continue contributing to funding research conducted outside the EU, and enable the 'Oxfords' and 'Cambridges' to carry on remaining the most successful EU grant recipients. Without a substantial UK contribution, it is unlikely this will become a popular venture with European publics, as these universities are already the wealthiest of all European public universities. However, whatever their benefits, 'payments' to Brussels are hugely unpopular with the current UK government (HM Government(b) 2018: 1), and will be scrutinised and negotiated at great lengths, losing more valuable time. Research and higher education are thus becoming an increasingly threatened hostage of political negotiations. In the meantime, cutting-edge learning, research and science, for which the economic and societal benefits are evident, are losing out.

Acknowledgements The support of the Economic and Social Research Council (UK), the Office for Students (UK) and Research England (UK) (grant reference ES/R000166/1) is gratefully acknowledged along with the support from the Centre for Global Higher Education, University College London, London, UK.

Open Access This article is distributed under the terms of the Creative Commons Attribution 4.0 International License (http://creativecommons.org/licenses/by/4.0/), which permits unrestricted use, distribution, and reproduction in any medium, provided you give appropriate credit to the original author(s) and the source, provide a link to the Creative Commons license, and indicate if changes were made.

\section{References}

British Academy. (2017). Brexit Means...? The British Academy's priorities for the humanities and social sciences in the current negotiations, November 2017.

De la Baume, M., \& Mishcke, J. (2017). Barnier dashes Britain's trade hopes. Politico, 16 November 2017, https://www.politico.eu/article/brexit-trade-barnier-dashes-britains-hopes-of-something-better-than-canada-deal/. Accessed 30 Aug 2018. 
European Commission(a) (2014). Directorate-General for research \& innovation, associated countries, http://ec.europa.eu/research/participants/data/ref/h2020/grants_manual/hi/3cpart/h2020-hi-list-ac_en.pdf. Accessed 30 Aug 2018.

European Commission(b). (2017). Interim evaluation of Horizon 2020: Annex 1, commission staff working document, SWD(2017) 221 final, 29 May 2017, https://ec.europa.eu/transparency/regdoc/rep/10102/2017 /EN/SWD-2017-221-F1-EN-MAIN-PART-4.PDF. Accessed 30 Aug 2018.

European Commission(c). (2017) LAB-FAB-APP: Investing in the European future we want, July 2017, https://ec.europa.eu/info/sites/info/files/conferences/sof/hlg_2017_report.pdf. Accessed 30 Aug 2018.

European Commission(d). (2017). Directorate-general for Research \& Innovation: Participant portal, News for British applicants to Horizon 2020, 06 October 2017, http://ec.europa. eu/research/participants/portal/desktop/en/support/about.html. Accessed 30 Aug 2018.

European Commission(e). (2018). Draft withdrawal agreement on the withdrawal of the United Kingdom of Great Britain and Northern Ireland from the European Union and the European atomic energy community, 28 February 2018, TF50 33.

European Commission(f) (2018) Directorate-general for research \& innovation: participant portal, Horizon 2020 data: Horizon 2020 interactive dashboard, 29 September 2018, http://ec.europa. eu/research/participants/portal/desktop/en/projectresults/index.html. Accessed 29 Sept 2018.

Fox, L. (2018). No deal most likely Brexit outcome for UK. BBC, 05 https://www.bbc.com/news/uk-politics45073294. Accessed 30 Aug 2018.

Her Majesty's Government(a). (2017), Collaboration on science and innovation: a future partnership paper, 6 September 2017, https:/www.gov.uk/government/publications/collaboration-on-science-and-innovation-afuture-partnership-paper. Accessed 30 Aug 2018.

Her Majesty's Government(b). (2018). The future relationship between the United Kingdom and the European Union, Cm9593, July 2018.

Her Majesty's Government(c). (2018). Funding from EU programmes guaranteed until the end of 2020, 24 July 2018 , https://www.gov.uk/government/news/funding-from-eu-programmes-guaranteed-until-the-end-of-2020. Accessed 30 Aug 2018.

Highman, L. (2018). The EU's external engagement in higher education: Externalizing the Bologna process. In S. Gstöhl, S. Schunz, \& C. Damro (Eds.), The European Union's evolving external engagement: towards new sectoral diplomacies? Abingdon: Routledge.

Matthews, D. (2017). UK-led research with EU funding drops sharply after Brexit vote. Times Higher Education, 21 December 212017.

Papatsiba, V. \& Highman, L. (2017). Creating a new relationship in research, science and innovation with the $E U$. Centre for Global Higher Education policy briefings, policy briefing no. 3, November 2017.

Technopolis Group. (2017). The role of EU funding in UK research and innovation, May 2017.

Universities UK. (2017). International research collaboration after the UK leaves the European Union, April 2017, https://www.universitiesuk.ac.uk/policy-and-analysis/reports/Pages/internationalresearchcollaboration-post-exit.aspx. Accessed 30 Aug 2018. 